\title{
Weakening of the Tropical Atmospheric Circulation Response to Local Sea Surface Temperature Anomalies under Global Warming 0
}

\author{
PING HUANG \\ Center for Monsoon System Research, and LASG, Institute of Atmospheric Physics, Chinese \\ Academy of Sciences, Beijing, China \\ DONG CHEN \\ Plateau Atmosphere and Environment Key Laboratory of Sichuan Province, College of Atmospheric Sciences, \\ Chengdu University of Information Technology, Chengdu, China \\ JUN YING \\ State Key Laboratory of Satellite Ocean Environment Dynamics, Second Institute of Oceanography, \\ State Oceanic Administration, Hangzhou, China
}

(Manuscript received 15 March 2017, in final form 7 July 2017)

\begin{abstract}
In the tropics, the atmospheric circulation response to sea surface temperature (SST) anomalies is a crucial part of the tropical air-sea interaction-the primary process of tropical climate. How it will change under global warming is of great importance to tropical climate change. Here, it is shown that the atmospheric vertical circulation response to local SST anomalies will likely be weakened under global warming using 28 selected models from phase 5 of the Coupled Model Intercomparison Project. The weakening of the circulation response to SST anomalies is closely tied to the increased atmospheric stability under global warming, which increases at the same rate as the circulation response decreases-around $8 \%$ for $1 \mathrm{~K}$ of tropical-mean SST warming. The spatial pattern of background warming can modify-especially in the equatorial central-eastern Pacific-the spatial distribution of the changes in the circulation response. The atmospheric response to SST anomalies may increase where the local background warming is pronouncedly greater than the tropical mean. The general weakening of the atmospheric circulation response to SST anomalies leads to a decreased circulation response to the structured variability of tropical SST anomalies, such as the El Niño-Southern Oscillation and the Indian Ocean dipole. The decreased circulation response will offset some of the enhancement of the tropical rainfall response to these SST modes as a result of global-warming-induced moisture increase and also implies a decreased amplitude of the tropical air-sea interaction modes.
\end{abstract}

\section{Introduction}

In the tropics, positive SST anomalies can heat and humidify the atmospheric boundary layer, increasing the atmospheric instability and inducing active convection anomalies (Wu and Kirtman 2005; Wu et al. 2006; Emanuel 2007; Collins et al. 2010; Deser et al.

Supplemental information related to this paper is available at the Journals Online website: https://dx.doi.org/10.1175/ JCLI-D-17-0171.s1.

Corresponding author: Dr. Ping Huang, huangping@mail.iap.ac. $\mathrm{cn}$
2010; Schneider et al. 2010). The active convection anomalies induced by positive SST anomalies are often associated with convergent winds in the boundary layer and upward circulation anomalies in the free atmosphere. The convection and horizontal wind anomalies may feed back to the SST anomalies by influencing shortwave radiation, sea surface evaporation, oceanic heat transportation, and so on (Deser et al. 2010; Chiang and Friedman 2012). The ubiquitous air-sea interaction is the primary process of tropical climate, especially for the internal variability (Wu et al. 2006; Deser et al. 2010; Chiang and Friedman 2012). As a crucial part of the tropical airsea interaction, the atmospheric circulation response 
to SST anomalies is undoubtedly important to tropical climate. In general, the sensitivity of the atmospheric circulation response to SST anomalies depends on the background SST (Graham and Barnett 1987; Kleeman 1991; Wang and Li 1993; Emanuel 2007; Johnson and Xie 2010; Raymond and Herman 2011). In the tropics, the climatological distribution of SST and convection exhibits a nonlinear relationship. There is a wellknown SST threshold for convection (Graham and Barnett 1987; Johnson and Xie 2010). Convection is difficult to generate when the local SST is lower than the SST threshold, which is approximately equal to the tropical-mean SST (Graham and Barnett 1987; Johnson and Xie 2010).

Understanding how the sensitivity of the atmospheric circulation response to SST anomalies will change under global warming is crucial to understanding the changes in internal variability of tropical climate and their remote impacts (Philip and Van Oldenborgh 2006; Collins et al. 2010; Christensen et al. 2013). Previous studies have shown that the climatological mean tropical circulation could decrease under global warming, as a result of a faster increase in specific humidity (around $7.5 \%$ for each 1-K surface temperature increase following the ClausiusClapeyron relationship) than in net downward radiation (around 2\%-3\% K ${ }^{-1}$ ) (Held and Soden 2006; Schneider et al. 2010; Ma et al. 2017). The decrease in the climatological tropical circulation can also be understood as a result of the increased atmospheric stability under global warming (Schneider et al. 2010; Ma et al. 2012; Chou et al. 2013; Byrne and Schneider 2016). However, it is unclear whether the increased atmospheric stability will decrease the sensitivity of the tropical atmospheric circulation response to local SST anomalies.

Here, we use the 500-hPa vertical pressure velocity $\omega$ to represent the vertical atmospheric circulation (Held and Soden 2006; Vecchi and Soden 2007) and define the sensitivity of the tropical circulation response to local SST anomalies $\partial \omega / \partial T$ (hereafter $\omega^{\prime}$ ) by the regression of monthly circulation anomalies onto local SST anomalies. (Negative $\omega$ indicates upward motion, and negative $\omega^{\prime}$ indicates an upward response to positive SST anomalies.) We selected 28 models out of 32 models from phase 5 of the Coupled Model Intercomparison Project (CMIP5) that simulate a $\omega^{\prime}$ distribution similar to observations. The 28 selected models project that $\omega^{\prime}$ at the end of the twenty-first century (2071-2100) relative to the presentday climate (1971-2000) will very likely decrease. The weakening of the circulation response to SST anomalies is closely tied to the increased atmospheric stability under global warming, which increases at the same rate as the circulation response decreases-around $8 \%$ for $1 \mathrm{~K}$ of tropical-mean SST warming.

\section{Models and methods}

We used the historical and the representative concentration pathway 8.5 (RCP8.5) runs from 32 models of CMIP5 (https://esgf-node.llnl.gov/search/cmip5/; Taylor et al. 2012); they are ACCESS1.0, ACCESS1.3, BCC_ CSM1.1, BCC_CSM1.1(m), BNU-ESM, CanESM2, CCSM4, CESM1(BGC), CESM1(CAM5), CMCC-CESM, CMCC-CM, CMCC-CMS, CNRM-CM5, CSIRO Mk3.6.0, FGOALS-g2, GFDL CM3, GFDL-ESM2G, GFDLESM2M, GISS-E2-H, GISS-E2-R, HadGEM2-ES, IPSL-CM5A-LR, IPSL-CM5A-MR, IPSL-CM5B-LR, MIROC-ESM, MIROC-ESM-CHEM, MIROC5, MPIESM-LR, MPI-ESM-MR, MRI-CGCM3, NorESM1-M, and NorESM1-ME. (Acronym expansions are available online at http://www.ametsoc.org/PubsAcronymList, and see http://cmip-pcmdi.llnl.gov/cmip5/availability.html for model details.) The periods of 1971-2000 in the historical runs and 2006-2100 in the RCP8.5 runs were selected.

Monthly SST and $\omega$ from the CMIP5 models were used. The 95-yr period from 2006 to 2100 in the RCP8.5 runs was divided into fourteen 30-yr segments with 5-yr leaps: 2006$35,2011-40,2016-45, \ldots, 2071-2100$. All datasets in the models were interpolated onto a $2.5^{\circ} \times 2.5^{\circ}$ grid. The observed SST from the NOAA Extended Reconstructed Sea Surface Temperature, version 4 (ERSST.v4) (Huang et al. 2015), and $\omega$ from the NCEP-NCAR reanalysis dataset (Kalnay et al. 1996) were used to evaluate the response of $\omega$ to SST anomalies simulated in the models.

The tropical circulation was represented by the 500-hPa vertical pressure velocity (Held and Soden 2006; Vecchi and Soden 2007). This analysis was performed for the 30-yr period in the historical runs and the 30 -yr segments in the RCP8.5 runs. The annual cycle of the 30-yr mean was removed to calculate the monthly anomalies of SST and $\omega$ for each segment. The linear trends of the monthly anomalies of SST and $\omega$ were then removed. Figure 1 shows the relationship between the monthly anomalies of SST and $\omega$ in the observations and the historical runs over four typical tropical regions, which are marked in Fig. 2a. The $\omega$ anomalies are significantly correlated with the SST anomalies over the four regions. The significant linear correlation between local $\omega$ and SST anomalies are well simulated in the majority of the 32 CMIP5 models (Fig. S1 in the supplemental material). Although the $\omega$-SST relationship may not be exactly linear in every region and in every model (Graham and Barnett 1987; Ma et al. 2017), we only focus on the linear part of $\omega$ response to local SST anomalies in the present study because it is the primary feature of $\omega$ response to SST and can be suitably quantified. Therefore, we define the sensitivity of $\omega$ response 
(a) Indian Ocean

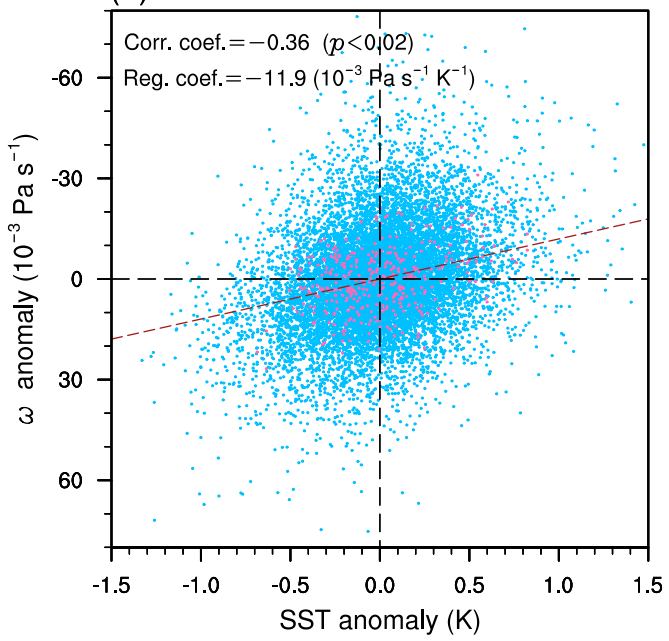

(c) eastern Pacific

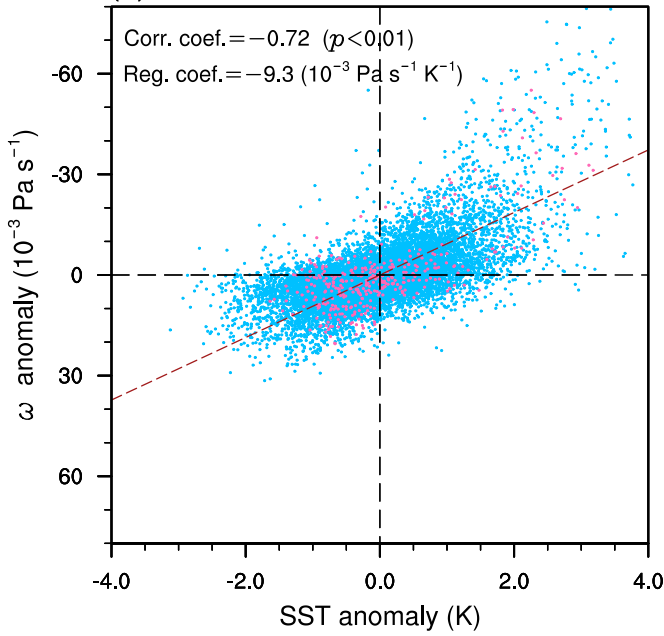

(b) western Pacific

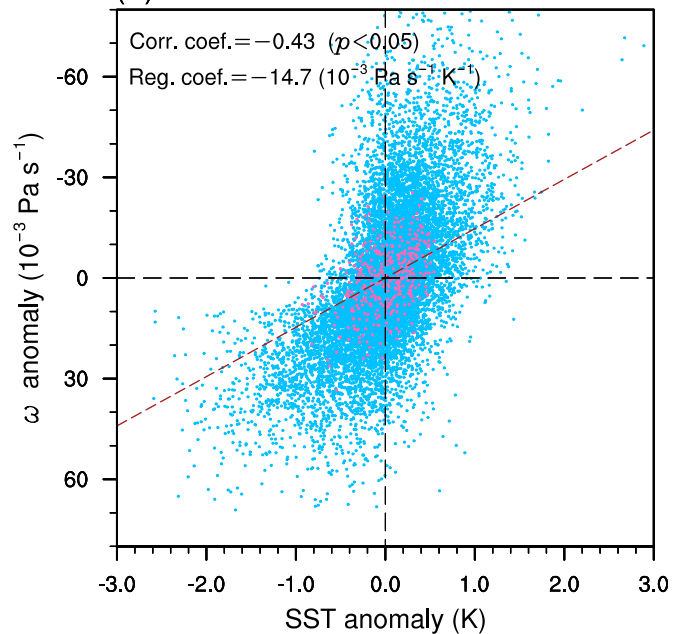

(d) Atlantic

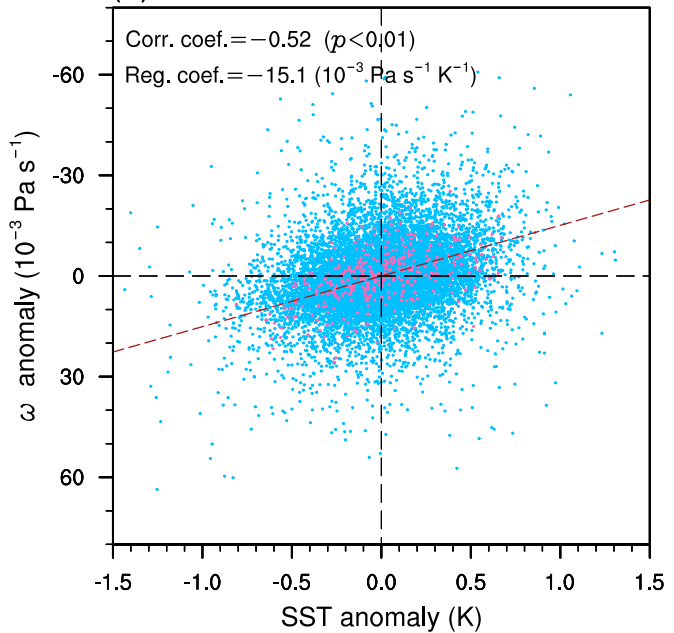

FIG. 1. Relationship between the monthly anomalies of circulation and local SST over four typical tropical regions: (a) the Indian Ocean $\left(5^{\circ} \mathrm{S}-5^{\circ} \mathrm{N}, 50^{\circ}-80^{\circ} \mathrm{E}\right)$, (b) the western Pacific $\left(5^{\circ} \mathrm{S}-5^{\circ} \mathrm{N}, 150^{\circ} \mathrm{E}-180^{\circ}\right)$, (c) the eastern Pacific $\left(5^{\circ} \mathrm{S}-5^{\circ} \mathrm{N}, 120^{\circ}-90^{\circ} \mathrm{W}\right)$, and $(\mathrm{d})$ the Atlantic $\left(5^{\circ} \mathrm{S}-5^{\circ} \mathrm{N}, 40^{\circ}-10^{\circ} \mathrm{W}\right)$. Each dot represents a pair of regionalmean $\omega$-SST anomalies in a month of the period 1971-2000. The blue dots denote the historical runs of the 32 CMIP5 models, the red dots denote the observations, and the red dashed lines are the linear regressions of the observational $\omega$ and SST anomalies. The correlation coefficient with the $p$ value and regression coefficient of the observational $\omega$ and SST anomalies is shown in the top-left corner of each panel.

to local SST anomalies $\omega^{\prime}$ (in units of $\mathrm{Pa} \mathrm{s}^{-1} \mathrm{~K}^{-1}$ ) by the linear regression of monthly $\omega$ anomalies onto the local SST anomalies, which means the circulation anomalies induced by $1-\mathrm{K}$ local SST anomalies. Negative $\omega^{\prime}$ indicates upward circulation anomalies in response to positive SST anomalies. The background SST was defined by the 30 -yr mean of SST for each scenario.

Of the 32 CMIP5 models, 28 were selected in the present study because 4 models-BCC_CSM1.1, FGOALS-g2, IPSL-CM5B-LR, and MRI-CGCM3-did not realistically reproduce the observed linear correlation between $\omega$ and SST anomalies (Fig. S1) and the observed $\omega^{\prime}$ in the historical runs (Fig. S2 in the supplemental material). In all 28 selected models, the uncentered pattern correlations between the modeled and observed $\omega^{\prime}$ are larger than 0.4 , and in 26 of the 28 models, the pattern correlations are larger than 0.6 (Fig. S2).

\section{Results}

\section{a. General weakening of $\omega^{\prime}$}

Figure 2a shows the defined $\omega^{\prime}$, which is larger in the high-background-SST regions than in the low-backgroundSST regions corresponding to the nonlinear SST-convection 
(a) $\omega^{\prime}$ $1971-2000$

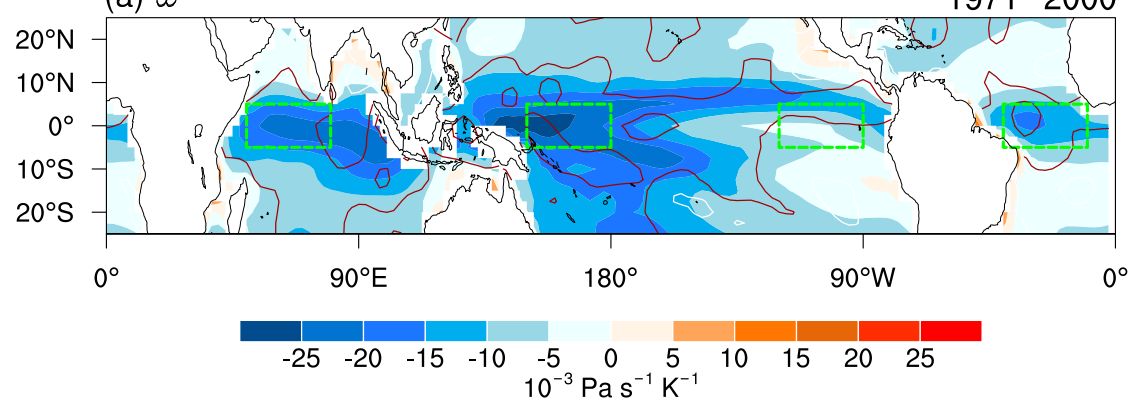

(b) $\Delta \omega^{\prime}$
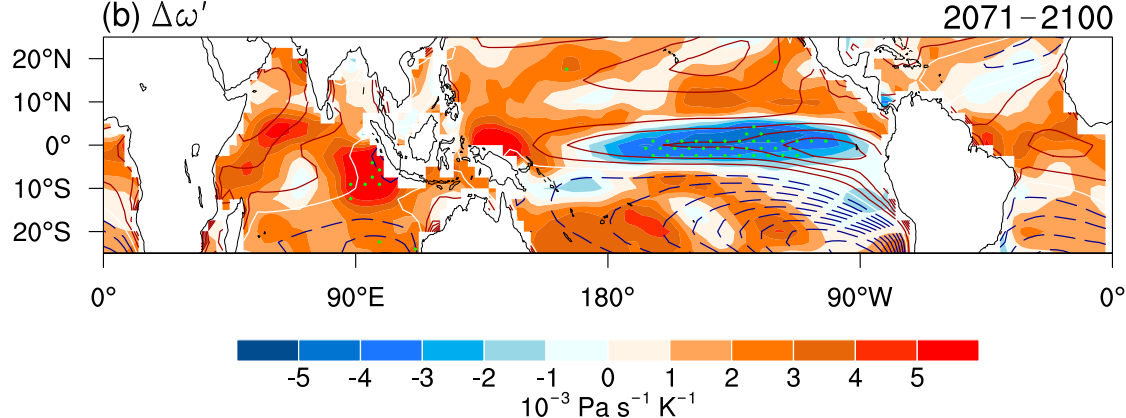

(c) Relative SST change

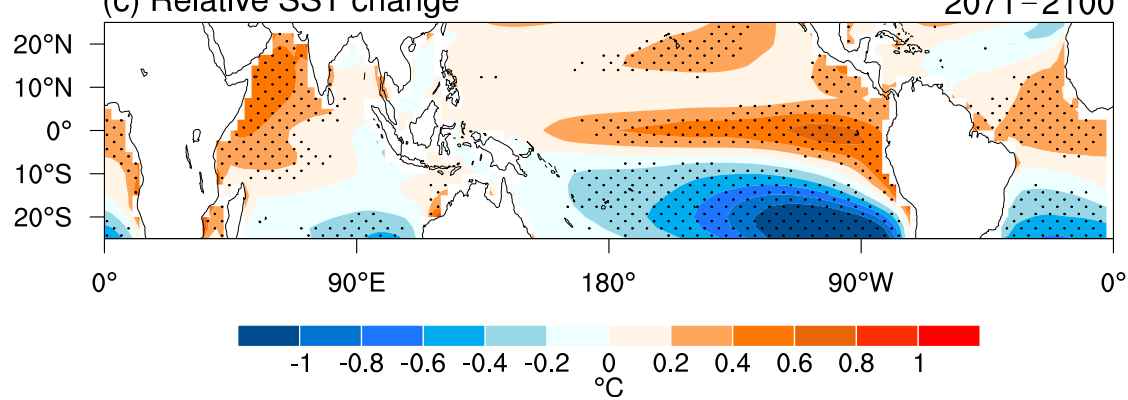

FIG. 2. (a) Spatial distribution of $\omega^{\prime}$ in the historical runs (1971-2000) of the MME of 28 selected models (shaded) and the observations (contours, with a contour interval of $10^{-2} \mathrm{~Pa} \mathrm{~s}^{-1} \mathrm{~K}^{-1}$ ). The green boxes in (a) indicate the four typical regions indicated in Fig. 1. (b) MME changes in $\omega^{\prime}$ (shaded) at the end of the twenty-first century (2071-2100) projected on the RCP8.5 scenario of the CMIP5 models. (c) Spatial pattern of background SST changes with the tropical-mean warming removed, which is the contours in (b), with a contour interval of $0.15 \mathrm{~K}$ and negative contours dashed. Stippling in (b) and (c) indicates that more than $80 \%$ of the 28 models agree on the sign of the MME changes.

relationship. The uncentered pattern correlation between $\omega^{\prime}$ in the multimodel ensemble (MME) of the 28 models and the observations is 0.84 . The $\omega^{\prime}$ is generally weakened around the tropics (Fig. 2b), with a narrow enhanced $\omega^{\prime}$ band in the equatorial central-eastern Pacific. However, the $\omega^{\prime}$ in individual models (Fig. S3 in the supplemental material) and the intermodel sign agreement test (Fig. 2b) show that the general weakening of $\omega^{\prime}$ in all models are not as clean as that in the MME. Furthermore, we find the enhanced $\omega^{\prime}$ in the MME is located in the regions with a relatively large background SST warming (contours in Fig. 2b), which is also a typical situation in the individual models (Fig. S3). This result implies that the spatial pattern of background SST warming possibly modifies the general weakening of $\omega^{\prime}$, which would be discussed in section $3 \mathrm{~b}$.

To remove the possible modification of background SST changes, $\omega^{\prime}$ of present-day and future climate are reorganized by the local background SST (Fig. 3a). In Fig. 3a, the background SST was binned at intervals of $0.5 \mathrm{~K}$. The grid numbers corresponding to each background SST bin $N_{i}(b)$ were counted, and $\omega^{\prime}$ in these grids $\omega_{i}^{\prime}(b)$ was averaged for the period $i$. The regions with historical $\omega^{\prime}$ less than $-5 \times 10^{-3} \mathrm{~Pa} \mathrm{~s}^{-1} \mathrm{~K}^{-1}$ 
(a)

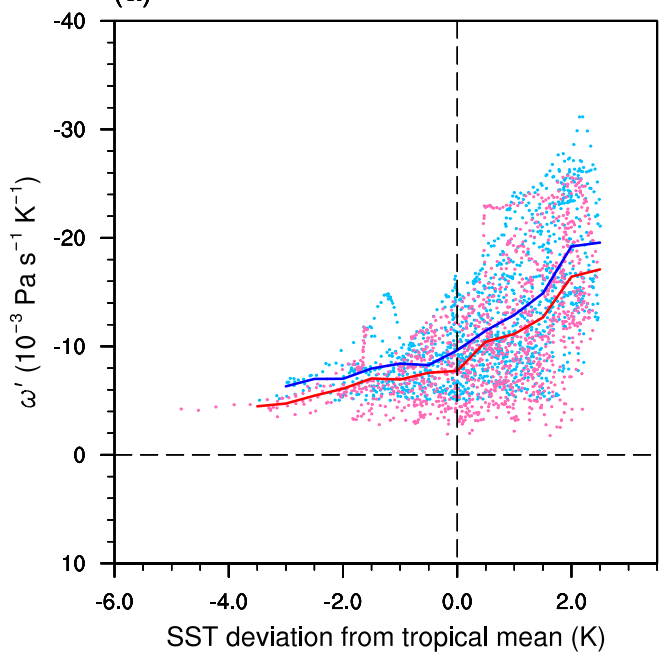

(b)

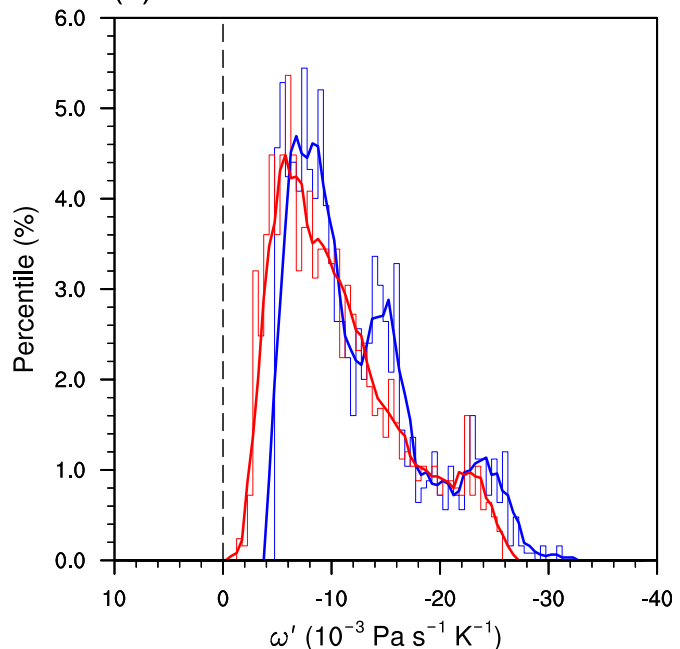

FIG. 3. General weakening of $\omega^{\prime}$ in a warming climate independent of location. (a) Relationship between $\omega^{\prime}$ and local background SST deviation from the tropical mean over the regions with historical $\omega^{\prime}$ less than $-5 \times 10^{-3} \mathrm{Pas}^{-1} \mathrm{~K}^{-1}$ in the MME of the historical (blue) and RCP8.5 (red) runs. Each dot in (a) represents a $\omega^{\prime}-\mathrm{SST}$ pair in a $2.5^{\circ} \times 2.5^{\circ}$ grid. The blue and red curves represent the averaged $\omega^{\prime}$ for the 0.5-K SST bins in the historical and RCP8.5 runs, respectively. (b) Percentiles of $\omega^{\prime}$ over the regions with historical $\omega^{\prime}$ less than $-5 \times 10^{-3} \mathrm{~Pa} \mathrm{~s}^{-1} \mathrm{~K}^{-1}$ in the MME of the historical (blue) and RCP8.5 (red) runs. Bars are the percentiles for the $-5 \times 10^{-4} \mathrm{~Pa} \mathrm{~s}^{-1} \mathrm{~K}^{-1} \omega^{\prime}$ bins and the curves are their five-point running averages.

were analyzed, which implies that the SST anomalies' processes influencing the atmosphere dominate the local air-sea interaction (Wu et al. 2006). The tropical-mean SST is removed in Fig. 3a to eliminate the influence of changes in the SST threshold on convection, as the increase in tropical-mean SST under global warming would increase the convection threshold (Johnson and Xie 2010). As a result, the future $\omega^{\prime}$ can be compared with the present-day $\omega^{\prime}$ under the same background SST deviating from the tropical-mean SST, eliminating the influence of local background SST changes. This analysis was performed for the MME of the 28 models (Fig. 3a) and for each model (Fig. S4 in the supplemental material).

The MME of the 28 models projects that $\omega^{\prime}$ in a warming climate (red dots and curve in Fig. 3a) is pronouncedly weaker than that in the present-day climate (blue dots and curve) under the same background SST. The decreased $\omega^{\prime}$ is robust among the models, as illustrated in each of the 28 selected models (Fig. S4). The percentiles of $\omega^{\prime}\left(\leq-5 \times 10^{-3} \mathrm{~Pa} \mathrm{~s}^{-1} \mathrm{~K}^{-1}\right)$ in the present-day and future climate are shown in Fig. 3b, which is also independent of region. The percentiles of $\omega^{\prime}$ also show a robust weakening in the MME (Fig. 3b) and in individual models (Fig. S5 in the supplemental material).

A hypothesized reason for the decreased $\omega^{\prime}$ is the increased atmospheric stability under global warming (Held and Soden 2006; Vecchi and Soden 2007;
Schneider et al. 2010; Zheng et al. 2010; Ma et al. 2012; Chou et al. 2013; Byrne and Schneider 2016). The tropical free atmosphere is close to a moist adiabat in the present-day and warming climate. On a moist adiabat, the variation of tropospheric-mean stability, measured by the vertical gradient of potential temperature $\partial \theta / \partial p$, is proportional to that of the near-surface specific humidity. As a result, the tropospheric-mean stability should increase under global warming with a change rate approximately equaling the increase rate of the near-surface specific humidity ( $\mathrm{Lu}$ et al. 2008). Under this hypothesis, the decrease rate of $\omega^{\prime}$ should equal the increase rate of near-surface specific humidity, around $7 \%-8 \%$ for each $1-K$ tropical-mean SST increase following the Clausius-Clapeyron relationship.

The simplest way to estimate the general changes of $\omega^{\prime}$ is to calculate the regional mean of tropical $\omega^{\prime}$ in Fig. 2b and Fig. S3. However, the simple regional mean in future climate could include the nonlinear effect of background SST changes. Therefore, we defined a weighted tropical mean $\left\langle\omega^{\prime}\right\rangle$ without the influence of nonuniform background SST changes in future climate. This definition was started from the relationship between $\omega^{\prime}$ and SST deviation from tropical mean in Fig. 3a. For the present climate (i.e., the historical runs) the weighted tropical-mean $\omega^{\prime}$ was calculated as $\left\langle\omega_{0}^{\prime}\right\rangle=\sum_{b=0}^{n} N_{0}(b) \omega_{0}^{\prime}(b) / \sum_{b=0}^{n} N_{0}(b)$, where $n$ is the number of all 0.5-K SST bins. Actually, the $\left\langle\omega_{0}^{\prime}\right\rangle$ equals the 
(a) 28 models

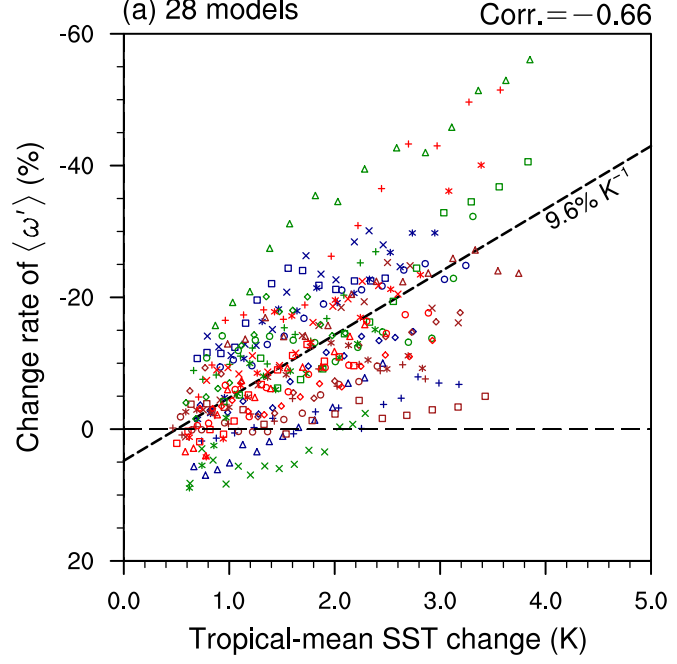

(b) MME

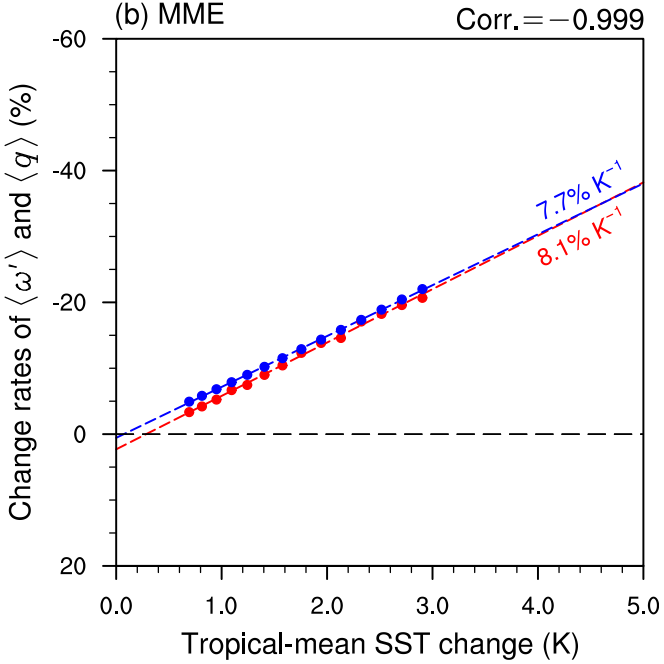

$*$ ACCESS1-0
+ ACCESS1-3
$\times$ bCC-csm1-1-m
$\diamond$ BNU-ESM

$\begin{array}{ll}\circ \text { CanESM2 } & + \text { CMCC-CESM } \\ \square \text { CCSM4 } & \times \text { CMCC-CM } \\ \triangle \text { CESM1-BGC } & \diamond \text { CMCC-CMS } \\ * \text { CESM1-CAM5 } & \circ \text { CNRM-CM5 }\end{array}$

$\square$ CSIRO-Mk3-6-0 $\times$ GISS-E2-H

$\triangle$ GFDL-CM3

* GFDL-ESM2G

$\diamond$ GISS-E2-R

$\triangle$ IPSL-CM5A-MR

$\diamond$ MPI-ESM-LR

+ GFDL-ESM2M

O HadGEM2-ES

$*$ MIROC-ESM

O MPI-ESM-MR

$\square$ IPSL-CM5A-LR

+ MIROC-ESM-CHEM

NorESM1-M

FIG. 4. Change rates of $\left\langle\omega^{\prime}\right\rangle$ with increasing tropical-mean SST. (a) The change rates of $\left\langle\omega^{\prime}\right\rangle$, in which the effect of the spatial pattern of background SST warming is removed, and the tropical-mean SST change in the 28 selected models for the fourteen 30-yr segments: 2006-35, 2011-40, .., 2071-2100. (b) The change rates of $\left\langle\omega^{\prime}\right\rangle$ (red dots) and the tropical-mean near-surface specific humidity $\langle q\rangle$ (blue dots) with the SST change in the MME of 28 selected models for the fourteen 30-yr segments. The dashed lines are the linear regressions of the change rates of $\left\langle\omega^{\prime}\right\rangle$ (red) and $\langle q\rangle$ (blue) on the SST increase, and the linear regression coefficients are shown in the respective colors. The correlation between the change rates of $\left\langle\omega^{\prime}\right\rangle$ and the SST changes is shown at the topright corner of each panel.

simple mean of all red dots in Fig. 3a. Moreover, in future periods, there is another issue that the varying background SST induces varying grid numbers for the background SST bins $N_{i}(b)$. Therefore, the $\left\langle\omega^{\prime}\right\rangle$ in the period $i$ was calculated using the averaged $\omega^{\prime}$ for the background SST bins $\omega_{i}^{\prime}(b)$ and weighted by the same grid numbers $N_{0}(b)$ in the historical runs as $\left\langle\omega_{i}^{\prime}\right\rangle=\sum_{b=0}^{n} N_{0}(b) \omega_{i}^{\prime}(b) / \sum_{b=0}^{n} N_{0}(b)$. The change rate of the tropical-mean $\omega^{\prime}$ for the period $i$ relative to that in the historical runs is $\left(\left\langle\omega_{i}^{\prime}\right\rangle-\left\langle\omega_{0}^{\prime}\right\rangle\right) /\left\langle\omega_{0}^{\prime}\right\rangle$.

Figure 4 shows the change rate of $\left\langle\omega^{\prime}\right\rangle$ during 14 future periods $(2006-35,2011-40, \ldots, 2075-2100)$ in the 28 selected models. The $\left\langle\omega^{\prime}\right\rangle$ exhibits a robust decrease with the increase in tropical-mean SST in all models. The decrease rate of $\left\langle\omega^{\prime}\right\rangle$ calculated based on all $392(=28 \times$ 14) cases is around $9.6 \% \mathrm{~K}^{-1}$ (Fig. 4a). The change rates of $\left\langle\omega^{\prime}\right\rangle$ in the individual models are shown in Fig. S6 of the supplemental material. When the change rate of $\left\langle\omega^{\prime}\right\rangle$ in the 28 models is averaged to reduce the influence of some outlier models, the decrease rate of the MME $\left\langle\omega^{\prime}\right\rangle$ in the 14 periods is around $8.1 \% \mathrm{~K}^{-1}$ (the red dots and line in Fig. 4b). The linear correlation coefficient between the decrease rate of MME $\left\langle\omega^{\prime}\right\rangle$ and the tropicalmean SST increase is very close to 1 . The MME change rate of $\left\langle\omega^{\prime}\right\rangle$ is very close to the increase rate of tropical- mean near-surface specific humidity in the tropics, which is around $7.7 \% \mathrm{~K}^{-1}$ (the blue dots and line in Fig. 4b) (Held and Soden 2006; O'Gorman and Muller 2010). This change rate implies that the increased atmospheric stability (Held and Soden 2006; Vecchi et al. 2006; Schneider et al. 2010) is reasonable and accurate in explaining the general weakening of $\omega^{\prime}$ under global warming. The decrease rate of $\left\langle\omega^{\prime}\right\rangle$ is larger than the decrease rate of mean-state circulation, which is around $4 \%-5 \% \mathrm{~K}^{-1}$. For the mean state, the rates of change of convective mass flux $M_{c}$, precipitation $P$, and near-surface specific humidity $q$ have an approximate relationship as follows: $\Delta M_{c} / M_{c}=\Delta P / P-\Delta q / q$ (Held and Soden 2006), in which the precipitation must increase following the increase rate in $\mathrm{CO}_{2}$-induced downward radiation due to the constraint of global energy balance (Held and Soden 2006; Vecchi et al. 2006; Schneider et al. 2010). As a result, the decrease rate of mean-state circulation is less than the increase rate of near-surface specific humidity. However, there is not a similar energy balance constraint for the local month-to-month variation, and thus the change rate of $\left\langle\omega^{\prime}\right\rangle$ is approximate to the increase rate of near-surface specific humidity. 


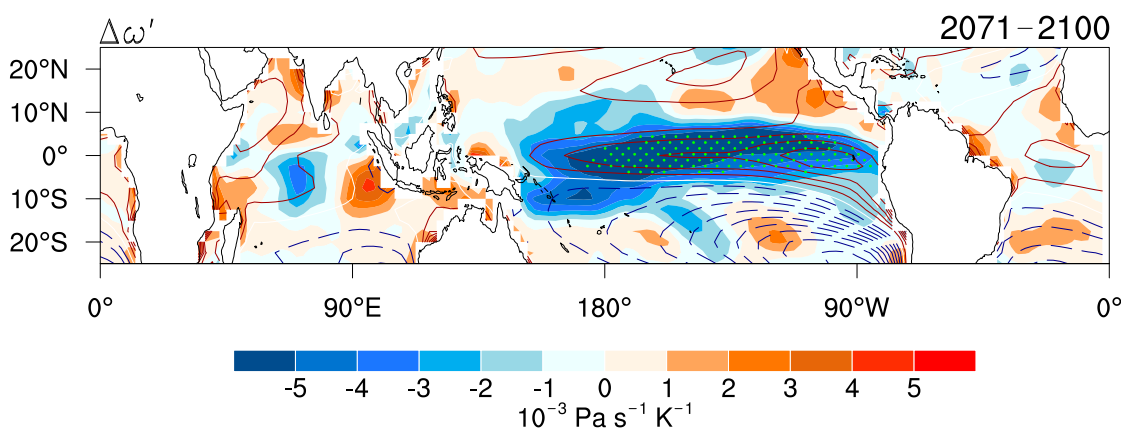

FIG. 5. As in Fig. 2b, but for the MME changes in $\omega^{\prime}$ in which the effect of the tropical-mean SST increases has been removed. Stippling indicates that more than $80 \%$ of the 28 models agree on the sign of the MME changes in $\omega^{\prime}$ without the effect of the tropical-mean SST increases.

\section{b. Effect of background SST changes}

As shown in Fig. 2b, the general weakening of $\omega^{\prime}$ could be modified by the background SST changes. For example, the $\omega^{\prime}$ is enhanced over the equatorial central-eastern Pacific with a relatively large background SST warming (Xie et al. 2010; Huang and Ying 2015). The area of the increased $\omega^{\prime}$ in the central-eastern Pacific (blue shading) is much smaller than the area where local SST increases are larger than tropical-mean warming (red contours), likely due to the general weakening of $\omega^{\prime}$. Moreover, the expected $\omega^{\prime}$ increases are not existent over the western Indian Ocean and the Atlantic, although the relatively large SST changes in the equatorial Atlantic and the western Indian Ocean is as robust as that in the equatorial central-eastern Pacific (Fig. 2c). The uncentered pattern correlation between the changes in $\omega^{\prime}$ and the spatial pattern of background SST changes is only -0.09 (statistically insignificant) in the MME and less than 0.1 in most of the individual models (Fig. S3).

Therefore, we first estimated the spatial pattern of the general weakening of $\omega^{\prime}$ using the present-day $\omega^{\prime}$ (Fig. S2), the change rate of $\left\langle\omega^{\prime}\right\rangle$ (Fig. S6), and the tropical-mean SST increases, given by $\Delta \omega_{\mathrm{gw}}^{\prime}=\omega^{\prime}\left(\Delta\left\langle\omega^{\prime}\right\rangle / \omega_{0}^{\prime}\right)\langle\Delta \mathrm{SST}\rangle$. The general weakening of $\omega^{\prime}$ associated with the tropical-mean SST increases $\Delta \omega_{\mathrm{gw}}^{\prime}$ is removed from the total $\Delta \omega^{\prime}$, and the residual $\Delta \omega^{\prime}$ is shown in Fig. 5 for MME and Fig. S7 in the supplemental material for individual models, in which the effect of the background SST changes is clearer. In Fig. 5, the enhanced $\omega^{\prime}$ over the equatorial central-eastern Pacific is more apparent and more consistent with the relative SST changes than that in Fig. $2 b$, and the enhanced $\omega^{\prime}$ can be found in the western Indian Ocean and the Atlantic. When the local SST warming is greater than the tropical mean warming, the consequent warmer and wetter air in the boundary layer will make the local atmosphere more unstable (Raymond and Herman 2011; Chou et al. 2013), which can be observed from the stronger historical $\omega^{\prime}$ in higher local mean-state SST regions shown in Figs. 2a and 3a.

The consistency between the residual $\Delta \omega^{\prime}$ and the relative SST changes mainly appears in the regions from $10^{\circ} \mathrm{S}$ to $10^{\circ} \mathrm{N}$ (Fig. 5). This conclusion can also be obtained from their spatial pattern correlation. Their uncentered pattern correlation from $25^{\circ} \mathrm{S}$ to $25^{\circ} \mathrm{N}$ is only -0.11 , whereas the correlation from $10^{\circ} \mathrm{S}$ to $10^{\circ} \mathrm{N}$ is up to -0.39 . This result can be explained by the regional dependence of the effect of background SST variations on $\omega^{\prime}$. From Fig. 3a, the slope of $\omega^{\prime}$ in negative SST deviation from tropical mean (the curves in the left side of the vertical dashed line) is smaller than the slope of $\omega^{\prime}$ in positive SST deviation. In other words, the $\omega^{\prime}$ is more sensitive to background SST variations when the background SST is larger than tropical mean, which is located around from $10^{\circ} \mathrm{S}$ to $10^{\circ} \mathrm{N}$ (not shown). Moreover, the effect of the background SST changes to enhance $\omega^{\prime}$ over the equatorial central-eastern Pacific is pronouncedly stronger than that over the equatorial Indian Ocean and Atlantic (Fig. 5). This result implies the relationship between the $\omega^{\prime}$ and background SST could depend on other factors, such as the background circulation, convection, and land-ocean distribution, which is worth further study in the future.

\section{c. Weakened circulation response to ENSO and IOD}

The general weakening of the tropical circulation response to local SST anomalies implies that the impacts of the structured variability of tropical SST anomalies on local tropical circulation are also likely weakened under global warming (Wu and Kirtman 2005; Philip and Van Oldenborgh 2006; Collins et al. 2010; Zheng et al. 2010; Cai et al. 2013; Huang and Chen 2017). Here, we study two dominant modes of the tropical SST variability simulated in the 28 models, ENSO in the tropical Pacific (Philander 1990; Neelin et al. 1998) and the Indian Ocean dipole (IOD) in the tropical Indian Ocean (Saji et al. 1999; Webster et al. 1999). 


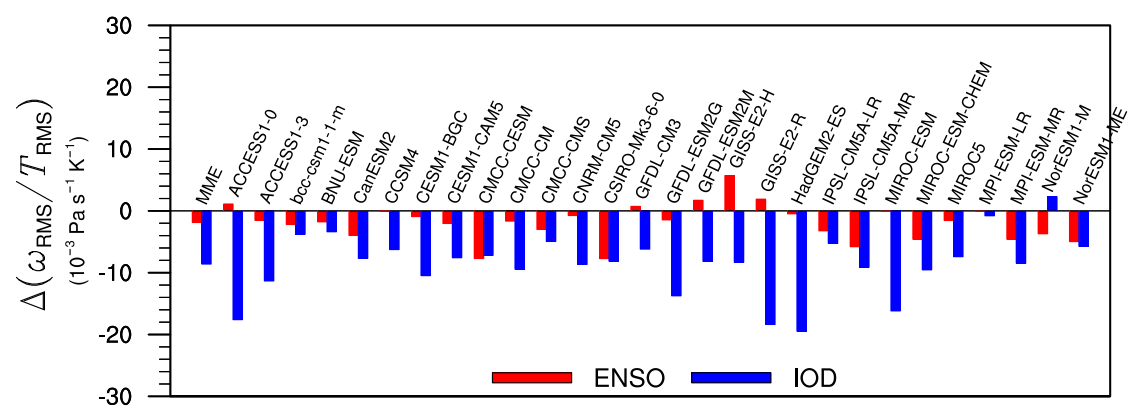

FIG. 6. Changes in the strength of the tropical circulation response to two tropical SST modes, ENSO (red) and the IOD (blue), in the 28 selected models and their MME.

The spatial pattern of ENSO-related SST anomalies in each model and each scenario was defined by the first empirical orthogonal function (EOF) mode of the interannual anomalies of tropical Pacific SST $\left(15^{\circ} \mathrm{S}-15^{\circ} \mathrm{N}\right.$, $120^{\circ} \mathrm{E}-80^{\circ} \mathrm{W}$ ). The EOF mode was scaled by the standard deviation of the corresponding principal component. The ENSO-driven tropical circulation anomalies were defined by the regression of $500-\mathrm{hPa}$ vertical pressure velocity anomalies onto the standardized principal component. The spatial patterns of ENSO-related SST and circulation anomalies are likely changed under global warming, but their projection show large intermodel uncertainties (Collins et al. 2010; Cai et al. 2015). To simplify the problem, we only focus on the amplitude changes in ENSOrelated SST and circulation without their spatial structure changes. The amplitude changes in ENSO-related SST and circulation were defined by the ENSO-related SST and circulation in the RCP8.5 projected onto their respective patterns in the historical runs. The definition of the amplitude changes are the same as in Huang and Xie (2015). The spatial root-mean-square of ENSO-driven circulation anomalies $\omega_{\mathrm{RMS}}$ and SST anomalies $T_{\mathrm{RMS}}$ were calculated to represent the strength of the ENSO-related patterns, and then the ratio of $\omega_{\mathrm{RMS}}$ to $T_{\mathrm{RMS}}\left(\omega_{\mathrm{RMS}} / T_{\mathrm{RMS}}\right)$ defines the sensitivity of the local circulation response to SST modes in different periods. The definitions of SST and $\omega$ anomalies for the IOD were similar to those for ENSO except that the domain was $25^{\circ} \mathrm{S}-25^{\circ} \mathrm{N}, 30^{\circ}-120^{\circ} \mathrm{E}$ and that the standardized dipole mode index (DMI) - the different SST anomalies in the west $\left(10^{\circ} \mathrm{S}-10^{\circ} \mathrm{N}, 50^{\circ}-70^{\circ} \mathrm{E}\right)$ minus east $\left(10^{\circ} \mathrm{S}-0^{\circ}, 90^{\circ}-110^{\circ} \mathrm{E}\right)$ (Cai et al. 2013) -was used but not the standardized principal component.

The MME ENSO/IOD SST from the 28 models essentially reproduces the observed spatial patterns (Philander 1990; Neelin et al. 1998; Saji et al. 1999; Webster et al. 1999) (Fig. S8 in the supplemental material). The spatial structure changes in the ENSO/IOD SST and circulation have been removed to focus on their amplitude changes (Fig. S9 in the supplemental material) (Huang and Xie 2015).
Figure 6 shows the changes in $\omega_{\mathrm{RMS}} / T_{\mathrm{RMS}}$ for ENSO and IOD in 2071-2100 relative to 1971-2000. The MME changes in $\omega_{\mathrm{RMS}} / T_{\mathrm{RMS}}$ for ENSO and IOD both exhibit a decrease under global warming. Among the 28 models, 20 models $(71 \%)$ project an apparent decrease in $\omega_{\mathrm{RMS}} / T_{\mathrm{RMS}}$ for ENSO, whereas three models (CCSM4, MIROC-ESM, and MPI-ESM-LR) project a very weak decrease and five models (ACCESS1.0, GFDL CM3, GFDLESM2M, GISS-E2-H, and GISS-E2-R) project an increased $\omega_{\mathrm{RMS}} / T_{\mathrm{RMS}}$ for ENSO. The decreased $\omega_{\mathrm{RMS}} / T_{\mathrm{RMS}}$ is quite robust among the models, despite the large uncertainty in the ENSO-related SST changes (Collins et al. 2010; Christensen et al. 2013). For IOD, 27 of the 28 models $(96 \%)$ project a decreased $\omega_{\mathrm{RMS}} / T_{\mathrm{RMS}}$, which is a very robust projection. The more robust decrease in $\omega_{\mathrm{RMS}} / T_{\mathrm{RMS}}$ for the IOD than ENSO is consistent with the distribution of the changes in $\omega^{\prime}$ shown in Figs. $2 \mathrm{~b}$ and 5. In the Indian Ocean, $\omega^{\prime}$ exhibits a robust decrease (Fig. 2b) with a weak modification by the background SST change (Fig. 5), whereas the relatively large background SST changes in the equatorial Pacific enhance the circulation response to ENSO SST anomalies in a large portion of models (Figs. S3 and S7) to offset part of the weakening as a result of the increase in atmospheric stability. The robust weakening of the atmospheric circulation response to ENSO/IOD SST is consistent with results from a few previous studies using different models and scenarios (Philip and Van Oldenborgh 2006; Zheng et al. 2010; Huang and Chen 2017).

\section{Conclusions and discussion}

The tropical air-sea interaction is the core of tropical climate variability, such as the El Niño-Southern Oscillation and the Indian Ocean dipole. The atmospheric circulation response to sea surface temperature (SST) anomalies is a crucial part of the tropical air-sea interaction. Therefore, understanding the changes in the atmospheric circulation response to SST anomalies is key to understanding the changes in tropical climate 
variability. In the present study, we use the 500 -hPa vertical pressure velocity $\omega$ to represent the vertical atmospheric circulation and define the sensitivity of the tropical circulation response to local SST anomalies $\omega^{\prime}$ by the regression of monthly circulation anomalies onto local SST anomalies. We select 28 from 32 CMIP5 models that realistically reproduced the observed $\omega^{\prime}$. The changes in the tropical $\omega^{\prime}$ show two main characteristics, the general weakening of tropical-mean changes along with global warming and the spatial nonuniform changes dominated by the spatial pattern of background SST changes.

The tropical-mean response of circulation to local SST anomalies will very likely be weakened under global warming, at a rate of around $8 \%$ for $1 \mathrm{~K}$ of tropical-mean SST warming. In the tropics, the free atmosphere is close to a moist adiabat, so the variation of tropospheric-mean stability is proportional to that of the near-surface specific humidity. Under global warming, the tropospheric-mean stability increases with a rate approximately equaling the increase rate of the near-surface specific humidity $(\mathrm{Lu}$ et al. 2008), around $7 \%-8 \% \mathrm{~K}^{-1}$ following the ClausiusClapeyron relationship. The same change rate of the decrease in the circulation response and the increase in the near-surface specific humidity suggests that the weakening of the circulation response to SST anomalies is induced by the robust increase in atmospheric stability. The decrease rate of $\omega^{\prime}$ is larger than the decrease rate of mean-state circulation under global warming, around $4 \%-5 \% \mathrm{~K}^{-1}$ (Held and Soden 2006; Vecchi and Soden 2007). This could be because the increase in $\mathrm{CO}_{2}$-induced downward radiation favors an increased mean-state circulation, but there is not a similar radiation increase in the month-to-month variation of circulation.

The general weakening of the tropical circulation is not spatially uniform, which can be modified by the spatial pattern of background SST changes. The background SST changes enhance the circulation response to SST anomalies when the local background SST increases are larger than tropical-mean warming. When the local SST warming is greater than the tropical mean warming, the consequent warmer and wetter air in the boundary layer will make the local atmosphere more unstable (Raymond and Herman 2011; Chou et al. 2013). The regions with relatively large background SST increases include the equatorial central-eastern Pacific, the western Indian Ocean, and the equatorial Atlantic.

The general weakening of the circulation response to local SST anomalies leads to a reduced circulation response to two modes of the tropical SST variability, ENSO and the IOD. The reduced circulation response to the tropical SST modes will cancel out part of the increase in the local rainfall response to these SST modes, resulting from the increased specific humidity under global warming (Power et al. 2013; Cai et al. 2014b,a; Huang and Xie 2015). As a crucial part of the tropical coupled air-sea interaction (Wu and Kirtman 2005; Collins et al. 2010), the weakening of the atmospheric circulation response to local SST anomalies is a robust factor that contributes to decrease the amplitude of other tropical air-sea interaction modes (Philip and Van Oldenborgh 2006; Collins et al. 2010; Christensen et al. 2013; Huang and Xie 2015).

Although the general weakening of $\omega^{\prime}$ is robust among the models with a MME decrease rate of $8 \% \mathrm{~K}^{-1}$, the decrease rates of $\omega^{\prime}$ in the models show a remarkable intermodel spread (Fig. 4a and Fig. S6). The intermodel spread of the increase rate of $\omega^{\prime}$ could involve various aspects of the models, such as the climatological changes in the atmospheric vertical structure, the change rate of the specific humidity, the background SST changes, and the estimation methods. Moreover, the effect of background SST changes is more pronounced in the equatorial central-eastern Pacific than in the equatorial western Indian Ocean and the Atlantic (Fig. 5). The intermodel spread of the general weakening rate and the regional discrepancy of the effect of background SST changes imply that some other factors may exist to influence the changes in $\omega^{\prime}$ except the two mechanisms revealed in the present study, which is worth further study in the future.

Acknowledgments. The work was supported by the National Natural Science Foundation of China (41575088), the National Basic Research Program of China (2014CB953903), the National Natural Science Foundation of China (41461164005), the Foundation of CUIT (KYTZ201602), and the Youth Innovation Promotion Association of CAS. Dr. Ying was supported by the National Natural Science Foundation of China (41690121 and 41690120). The World Climate Research Programme's Working Group on Coupled Modelling, which is responsible for CMIP5, and the climate modeling groups are acknowledged for producing and making available their model output. We thank RCEC/Academia Sinica for distributing CMIP5 output. We thank NOAA/OAR/ESRL PSD for providing NCEP-NCAR reanalyses (https://www.esrl.noaa.gov/psd/data/gridded/ data.ncep.reanalysis.html) and NOAA ERSST.v4 data (https://www.esrl.noaa.gov/psd/data/gridded/data.noaa.ersst. v4.html). We also thank the three anonymous reviewers for their constructive suggestions.

\section{REFERENCES}

Byrne, M. P., and T. Schneider, 2016: Narrowing of the ITCZ in a warming climate: Physical mechanisms. Geophys. Res. Lett., 43, 11350-11 357, doi:10.1002/2016GL070396. 
Cai, W., X.-T. Zheng, E. Weller, M. Collins, T. Cowan, M. Lengaigne, W. Yu, and T. Yamagata, 2013: Projected response of the Indian Ocean dipole to greenhouse warming. Nat. Geosci., 6, 999-1007, doi:10.1038/ngeo2009.

, A. Santoso, G. Wang, E. Weller, L. Wu, K. Ashok, Y. Masumoto, and T. Yamagata, 2014a: Increased frequency of extreme Indian Ocean dipole events due to greenhouse warming. Nature, 510, 254-258, doi:10.1038/nature13327.

, and Coauthors, 2014b: Increasing frequency of extreme El Niño events due to greenhouse warming. Nat. Climate Change, 4, 111-116, doi:10.1038/nclimate2100.

and Coauthors, 2015: ENSO and greenhouse warming. Nat. Climate Change, 5, 849-859, doi:10.1038/nclimate2743.

Chiang, J. C. H., and A. R. Friedman, 2012: Extratropical cooling, interhemispheric thermal gradients, and tropical climate change. Annu. Rev. Earth Planet. Sci., 40, 383-412, doi:10.1146/ annurev-earth-042711-105545.

Chou, C., T.-C. Wu, and P.-H. Tan, 2013: Changes in gross moist stability in the tropics under global warming. Climate Dyn., 41, 2481-2496, doi:10.1007/s00382-013-1703-2.

Christensen, J. H., and Coauthors, 2013: Climate phenomena and their relevance for future regional climate change. Climate Change 2013: The Physical Science Basis, T. F. Stocker et al., Eds., Cambridge University Press, 1217-1308.

Collins, M., and Coauthors, 2010: The impact of global warming on the tropical Pacific ocean and El Niño. Nat. Geosci., 3, 391397, doi:10.1038/ngeo868.

Deser, C., M. A. Alexander, S.-P. Xie, and A. S. Phillips, 2010: Sea surface temperature variability: Patterns and mechanisms. Annu. Rev. Mar. Sci., 2, 115-143, doi:10.1146/ annurev-marine-120408-151453.

Emanuel, K., 2007: Quasi-equilibrium dynamics of the tropical atmosphere. The Global Circulation of the Atmosphere, T. Schneider and A. H. Sobel, Eds., Princeton University Press, 186-218.

Graham, N., and T. P. Barnett, 1987: Observations of sea surface temperature and convection over tropical oceans. Science, 238, 657-659, doi:10.1126/science.238.4827.657.

Held, I. M., and B. J. Soden, 2006: Robust responses of the hydrological cycle to global warming. J. Climate, 19, 5686-5699, doi:10.1175/JCLI3990.1.

Huang, B., and Coauthors, 2015: Extended Reconstructed Sea Surface Temperature version 4 (ERSST.V4). Part I: Upgrades and intercomparisons. J. Climate, 28, 911-930, doi:10.1175/ JCLI-D-14-00006.1.

Huang, P., and S.-P. Xie, 2015: Mechanisms of change in ENSOinduced tropical Pacific rainfall variability in a warming climate. Nat. Geosci., 8, 922-926, doi:10.1038/ngeo2571.

- and J. Ying, 2015: A multimodel ensemble pattern regression method to correct the tropical Pacific SST change patterns under global warming. J. Climate, 28, 4706-4723, doi:10.1175/ JCLI-D-14-00833.1.

— , and D. Chen, 2017: Enlarged asymmetry of tropical Pacific rainfall anomalies induced by El Niño and La Niña under global warming. J. Climate, 30, 1327-1343, doi:10.1175/JCLI-D-16-0427.1.

Johnson, N. C., and S.-P. Xie, 2010: Changes in the sea surface temperature threshold for tropical convection. Nat. Geosci., 3, 842-845, doi:10.1038/ngeo1008.

Kalnay, E., and Coauthors, 1996: The NCEP/NCAR 40-Year Reanalysis Project. Bull. Amer. Meteor. Soc., 77, 437-471, doi:10.1175/1520-0477(1996)077<0437:TNYRP>2.0.CO;2.

Kleeman, R., 1991: A simple model of the atmospheric response to ENSO sea surface temperature anomalies. J. Atmos. Sci., 48 , 3-19, doi:10.1175/1520-0469(1991)048<0003:ASMOTA >2.0.CO;2.
Lu, J., G. Chen, and D. M. W. Frierson, 2008: Response of the zonal mean atmospheric circulation to El Niño versus global warming. J. Climate, 21, 5835-5851, doi:10.1175/2008JCLI2200.1.

Ma, J., S.-P. Xie, and Y. Kosaka, 2012: Mechanisms for tropical tropospheric circulation change in response to global warming. J. Climate, 25, 2979-2994, doi:10.1175/JCLI-D-11-00048.1.

—, R. Chadwick, K.-H. Seo, C. Dong, G. Huang, G. R. Foltz, and J. H. Jiang, 2017: Responses of the tropical atmospheric circulation to climate change and connection to the hydrological cycle. Annu. Rev. Earth Planet. Sci., in press.

Neelin, J., D. Battisti, A. Hirst, F. Jin, Y. Wakata, T. Yamagata, and S. Zebiak, 1998: ENSO theory. J. Geophys. Res., 103, 14 261-14290, doi:10.1029/97JC03424.

O'Gorman, P. A., and C. J. Muller, 2010: How closely do changes in surface and column water vapor follow Clausius-Clapeyron scaling in climate change simulations? Environ. Res. Lett., 5 , 025207, doi:10.1088/1748-9326/5/2/025207.

Philander, S. G., 1990: El Niño, La Niña, and the Southern Oscillation. Academic Press, 293 pp.

Philip, S., and G. Van Oldenborgh, 2006: Shifts in ENSO coupling processes under global warming. Geophys. Res. Lett., 33, L11704, doi:10.1029/2006GL026196.

Power, S., F. Delage, C. Chung, G. Kociuba, and K. Keay, 2013: Robust twenty-first-century projections of El Niño and related precipitation variability. Nature, 502, 541-545, doi:10.1038/nature12580.

Raymond, D. J., and M. J. Herman, 2011: Convective quasiequilibrium reconsidered. J. Adv. Model. Earth Syst., 3, M08003, doi:10.1029/2011ms000079.

Saji, N., B. Goswami, P. Vinayachandran, and T. Yamagata, 1999: A dipole mode in the tropical Indian Ocean. Nature, 401, 360-363.

Schneider, T., P. A. O'Gorman, and X. J. Levine, 2010: Water vapor and the dynamics of climate changes. Rev. Geophys., 48 RG3001, doi:10.1029/2009RG000302.

Taylor, K. E., R. J. Stouffer, and G. A. Meehl, 2012: An overview of CMIP5 and the experiment design. Bull. Amer. Meteor. Soc., 93, 485-498, doi:10.1175/BAMS-D-11-00094.1.

Vecchi, G. A., and B. J. Soden, 2007: Global warming and the weakening of the tropical circulation. J. Climate, 20, 43164340, doi:10.1175/JCLI4258.1.

, A. T. Wittenberg, I. M. Held, A. Leetmaa, and M. J. Harrison, 2006: Weakening of tropical Pacific atmospheric circulation due to anthropogenic forcing. Nature, 441, 73-76, doi:10.1038/nature04744.

Wang, B., and T. Li, 1993: A simple tropical atmosphere model of relevance to short-term climate variations. J. Atmos. Sci., 50, 260 284, doi:10.1175/1520-0469(1993)050<0260:ASTAMO>2.0.CO;2.

Webster, P. J., A. M. Moore, J. P. Loschnigg, and R. R. Leben, 1999: Coupled ocean-atmosphere dynamics in the Indian Ocean during 1997-98. Nature, 401, 356-360, doi:10.1038/43848.

Wu, R., and B. P. Kirtman, 2005: Roles of Indian and Pacific Ocean air-sea coupling in tropical atmospheric variability. Climate Dyn., 25, 155-170, doi:10.1007/s00382-005-0003-x.

$\longrightarrow,-$, and K. Pegion, 2006: Local air-sea relationship in observations and model simulations. J. Climate, 19, 4914-4932, doi:10.1175/JCLI3904.1.

Xie, S.-P., C. Deser, G. A. Vecchi, J. Ma, H. Teng, and A. T. Wittenberg, 2010: Global warming pattern formation: Sea surface temperature and rainfall. J. Climate, 23, 966-986, doi:10.1175/2009JCLI3329.1.

Zheng, X.-T., S.-P. Xie, G. A. Vecchi, Q. Liu, and J. Hafner, 2010: Indian Ocean dipole response to global warming: Analysis of ocean-atmospheric feedbacks in a coupled model. J. Climate, 23, 1240-1253, doi:10.1175/2009JCLI3326.1. 